\title{
Capacity building of health professionals on omics sciences: evaluation of the effectiveness of a distance learning training course for Italian physicians.
}

Giovanna Elisa Calabrò

Universita Cattolica del Sacro Cuore

Alessia Tognetto ( $\sim$ alessia.tognetto@gmail.com )

Catholic University of the Sacred Heart https://orcid.org/0000-0003-2140-9051

Alfonso Mazzaccara

Istituto Superiore Di Sanita

Donatella Barbina

Istituto Superiore Di Sanita

Pietro Carbone

Istituto Superiore Di Sanita

Debora Guerrera

Istituto Superiore Di Sanita

Alessandra Di Pucchio

Istituto Superiore Di Sanita

Antonio Federici

Ministero della Salute

Walter Ricciardi

Universita Cattolica del Sacro Cuore

Stefania Boccia

Universita Cattolica del Sacro Cuore

Research article

Keywords: Distance learning, Capacity building, Omics sciences, Problem-based Learning, Genetics, Medical Education, Genomics literacy.

Posted Date: May 7th, 2020

DOI: https://doi.org/10.21203/rs.2.19470/v2 
License: (c) (i) This work is licensed under a Creative Commons Attribution 4.0 International License. Read Full License 


\section{Abstract}

Background. The rapid adoption of personalized medicine approaches in healthcare requires professionals to be able to manage the "omics revolution". In this context, the genetics/genomics literacy of healthcare professionals should be in line with the continuous advances in this field, in order to implement its potential implications for the diagnosis, control and treatment of diseases. The present study investigates the effectiveness of a distance learning course on genetics and genomics targeted at medical doctors.

Methods. In the context of a project funded by the Italian Ministry of Health, we developed a distance learning course, entitled Genetics and Genomics practice. The contents of the course were identified from a core curriculum in genetics for physicians and healthcare professionals, previously published. The course focused on genetic/genomic testing in clinical practice, pharmacogenomics and oncogenomic and was developed according to andragogical training methods (Problem-based Learning and Casebased Learning). We used a pre-test versus post-test study design to assess knowledge improvement on a set of 10 Multiple Choice Questions (MCQs). We analysed the proportion of correct answers for each question pre and post-test, as well as the mean score difference stratified by gender, age, professional status and medical discipline. Moreover, the same test was submitted to the participants eight months after the conclusion of the course (follow-up), in order to assess the retained knowledge.

Results. An important number of Italian physicians ( $N=1637)$ completed the course, most of which were primary care physicians $(20.8 \%)$, public health professionals $(11.5 \%)$ and specialist paediatricians $(10.6 \%)$. We reported an improvement in the proportion of correct answers for all of the 10 MCQs set at the post-test. The overall mean score to the questions significantly increased in the post-test, from 59.46 in the pre-test to 71.42 in the post-test ( $p$-value<0.0001). The comparison in test performance between follow-up and pre-test demonstrated an overall knowledge improvement.

Conclusions. Genomic literacy among healthcare professionals is essential to ensure optimal translation to healthcare delivery of research. The results of this course suggest that distance-learning training in genetic/genomic practices represents an effective method to improve physicians' knowledge in the immediate and mid-term time scale.

\section{Background}

The last two decades were characterized by a "genetic revolution" that has given rise to the "omics sciences era" as a consequence of the spread of high-throughput investigation techniques, capable of generating enormous amounts of data related to the different hierarchical levels of biological complexity (DNA, mRNA, proteins, metabolites, etc. ...) [1].

The rapid spread of this new knowledge requires healthcare professionals to manage the possible application of the omics sciences, ranging from medical research advances to use in screening, diagnosis and prognosis of different pathologies [2, 3]. 
While several European countries implemented dedicated health policies in this area [4], few countries have integrated Public Health Genomics into the health system offer [5], such as Italy where personalized medicine was included in the National Prevention Plans since $2010[6,7]$.

More recently, the Italian National Plan for innovation of the Health System based on omics sciences identified the educational efforts towards professionals, citizens and decision makers as a cornerstone for a proper implementation of omics sciences in healthcare [8]. In the context of Continuous Medical Education (CME), the Italian Ministry of Health has supported a course entitled "Genetics and Genomics practice" [9]. With the purpose of training medical professionals in the responsible use of omics technologies, a distance learning method was chosen. In recent years this method has increasingly become part of medical education programs and, besides allowing to reach a high number of learners, has shown to be effective in the context of CME [10].

Our study presents the project aimed at developing a distance learning course in genetics and genomics targeted to medical professionals and to evaluate its effectiveness in terms of knowledge improvement of participants after the course, and eight months after its closing.

\section{Methods}

\section{Elaboration of the scientific contents of the course}

The course included audio-video lectures and interactive clinical cases and was structured according to the main models of andragogical training (Problem-based Learning and Case-based Learning). The Problem-based Learning (PBL) is a training methodology that stimulates the participants to "learn to learn" by solving real-world problems that reflect their work context [11, 12]. The Case-based Learning $(\mathrm{CBL})$ is a teaching methodology used in medical education as an aid in connecting theory to practice [13].

The content of the course and the delivery model were identified according to two previous literature reviews: the first systematic and aimed at identifying the core competencies in genetics/genomics for non-genetics healthcare professionals [14], and the second aimed at identifying the most effective educational interventions to improve knowledge of health professionals in the "omics sciences" field [15]. The course topics were validated by a panel of expert geneticists involved as teachers of the course.

The general and specific objectives and the content of the course, including 9 case studies, are reported in Table 1.

Table 1. Objectives and content of the distance learning course "Genetics and Genomics practice". 

the responsible use of "omics" technologies.

Specific objectives

1. Identify the basic concepts of human genetics

2. Describe the main genetic / genomic tests currently available and their application

3. Describe the main applications of pharmacogenetic tests

4. Describe the main applications of genetic / genomic tests in oncology

5. Consciously manage clinical information, family history and genetic test results for optimal patient management (including possible specialist referral).

Topics

Case Studies

Public Health Genomics

Genetic tests in the clinical practice

1. Pulmonary disease, sinusitis, digital hippocratism (Atypical Cystic Fibrosis)

2. Unilateral maculopathy and predictive tests (example of predictive tests aimed directly at consumers)

3. Monitoring of pregnancy with "super-villocentesis" or "super-amniocentesis"

Pharmacogenetics

1. 4. Hypersensitivity to warfarin

2. Patient with insufficient response to antiplatelet therapy

3. Abacavir hypersensitivity syndrome

Oncology genomics

1. Hereditary breast cancer

2. Family history of multiple cancers

3. Hereditary colon cancer

Integration of genetic tests

into cancer screening

programs

Notes: GPs: General Practitioners; FPs: Family Pediatricians

\section{Course characteristic, learning methodology and participants}

The distance course "Genetics and Genomics practice" was accessible free of charge on the Italian National Institute of Health e-learning platform (EDUISS - https://www.eduiss.it). The Learning Management System (LMS) used was Totara Learn, that offered the technical resources to reproduce the selected methodological approaches (PBL and $\mathrm{CBL}$ ).

The course was delivered from February $27^{\text {th }}, 2017$ to February $1^{\text {st }}, 2018$. The course, open to all physicians potentially involved in the prescription and/or interpretation of genetic tests, was primarily targeted at General Practitioners (GPs) and Family Pediatricians (FPs). The maximum number of subscribers was 3500 . Successful completion of the course included the release of $30 \mathrm{CME}$ credits. 
Participants were expected to spend 30 hours to complete the course and could access the course at any time.

According to the Italian regulation, ethics approval was not required for this study: by registering for the course on the online platform, the participants gave the consent to the use of their anonymous data.

The course was structured in 4 sections:

1. Introductive section: introduction to the course explaining its relevance, general aims and structure; general objectives of the course; participants guide containing all the information needed to attend the course; preliminary self-assessment test to set the initial knowledge (pre-test) consisting in 10 Multiple Choice Questions (MCQs). No minimum score was required to complete the test.

2. PBL section (1 entire PBL cycle - 7 steps): problem presentation and analysis, specific learning objectives identification, bibliographical references and list of useful web sites to be consulted, reading materials to deepen the topics of the course, audio-video tutorials by experts and the solution of the problem.

3. Case Studies section: exercises on 9 different clinical cases (Table 1).

4. Conclusive section: post-test (same 10 MCQs set of the pre-test), final certification test, satisfaction questionnaire. Passing the final certification test, consisting in $90 \mathrm{MCQs}(0$ points for wrong answers - 1 point for correct answer) was mandatory to complete the course and get the CME credits. Each learning objective has been represented and tested in a set of MCQs. The passing mark was set at $75 \%$ of the scored questions answered correctly. Three passing attempts were allowed.

Despite some Authors point out that MCQs couldn't be fully appropriate to assess the competences acquired through PBL approach, as it should be based upon performance and not only upon giving correct answers [16], however MCQs tests can be considered suitable for self-assessment especially when required to assess a large amount of knowledge, as in the case in study [17]. Using MCQs tests was also appropriate since the assessment was directed to the levels of "understanding" and "remembering" [18], as expected in such an e-learning environment.

The course methodology integrated the PBL $[11,12]$ and the CBL [13], in order to satisfy the strong clinical orientation of the course. PBL has been successfully used in other distance learning courses targeted at health professionals by the same working group. Over the years PBL has been adapted to the e-learning context and different learning models have been developed, depending on the level of interaction between participants and facilitator $[9,12]$. In courses with high turnout the participants follow the steps of the PBL by their own, even if small groups or facilitator are not provided. In this course the entire PBL cycle was set up using platform tools such as feedback, web pages, quizzes. The first steps of the PBL cycle, consisting in problem analysis and learning objectives identification, were provided through an interactive tool that allowed to track the results of the participants. 
The case studies were realized through interactive exercises, consisting in clinical case audio-video presentations, animated slides, clinical notes and final questions on the case focal points.

\section{Data collection}

When registering for the course in the e-learning platform, the following demographic and professional information about the participants were collected from the system: gender, age, region of residence; CME discipline; professional status (National Health Service - NHS employee, freelancer, private contractors with NHS, unemployed). A preliminary question on the previous learning experience on genetics was proposed only at the beginning of the course. Afterwards, a pre-test of $10 \mathrm{MCQ}$ was performed in order to gain insight on genetic knowledge at course registration (TO). The same set of 10 MCQ was administered after the course (post-test, T1) before the CME certification test and was sent by e-mail to be repeated also eight months after the closure of the course (follow-up, T2) to those who had passed the course.

The test consisted of $10 \mathrm{MCQs}$ related to the different modules of the course. For those completing the test at $\mathrm{T} 2$, an additional question on the perceived competence about the capability to meet the patients requests on genetic tests was administered. At the very end of the course, participants who successfully completed the final certification test (consisting in $90 \mathrm{MCQs}$ ) were also required to fill in the satisfaction questionnaire (SQ), consisting in 18 closed questions about the perceived quality of the Learning Methodology, the educational Contents and the E-learning platform functioning.

\section{Statistical analysis}

We performed a descriptive analysis for demographic and professional information. The results of each question, for the pre-test, post-test and for the follow-up test, were reported as percentages of correct answers. The pre-test and post-test results were compared through the McNemar test. We calculated a score for the ten MCQs by assigning 10 points for each correct answer. The average scores of the pre-test and post-test were compared by $t$ test for paired data for the eligible participants. Data were stratified by gender, age categories, region of residence (North, Center, South and Islands), medical discipline and professional status. The discipline of the course participants was analyzed reporting individually those disciplines with more than $3 \%$ participants of the total, while those for which a lower percentage was recorded were grouped as "other specializations". The results of the follow-up test were analyzed by presenting the number and proportion of those who gave the correct answer to the test questions. The pre-test (T0) and follow-up results (T2) were compared through the McNemar test.

Statistical analysis was performed using the Stata software (StataCorp. 2013. Statistical Software: Release 13. College Station, TX: StataCorp. LP).

\section{Results}

\section{Course participants}


The participants who completed the course (Completers) were 1637 out of 3054 members enrolled (Figure 1).

Table 2 describes the characteristics of the Completers and of the 268 participants who filled in the follow-up test (Respondents).

Table 2. Characteristics of the participants who completed the course $(\mathrm{N}=1637)$ and of the Respondents at follow-up $(\mathrm{N}=268)$

\begin{tabular}{|c|c|c|}
\hline & $\begin{array}{c}\text { Completers } \\
\mathrm{N}=1637\end{array}$ & $\begin{array}{l}\text { Respondents at follow-up } \\
\qquad \mathrm{N}=268\end{array}$ \\
\hline Gender & Number (\%) & Number (\%) \\
\hline Male & $790(48.3)$ & $145(54.1)$ \\
\hline Female & $847(51.7)$ & $123(45.9)$ \\
\hline \multicolumn{3}{|l|}{ Age (years) } \\
\hline$<36$ & $111(6.7)$ & $11(4.1)$ \\
\hline $36-50$ & $458(28.0)$ & $63(23.5)$ \\
\hline $51-65$ & $954(58.3)$ & $171(63.8)$ \\
\hline$>65$ & $114(7.0)$ & $23(8.6)$ \\
\hline \multicolumn{3}{|l|}{ Italian Region area } \\
\hline North & $594(36.3)$ & $101(37.7)$ \\
\hline Center & $413(25.2)$ & $67(25)$ \\
\hline South & $630(38.5)$ & $100(37.3)$ \\
\hline \multicolumn{3}{|l|}{ Medical specialty } \\
\hline Primary care & $340(20.8)$ & $63(23.5)$ \\
\hline GPS & $226(13.8)$ & $35(13.0)$ \\
\hline FPs & $93(5.7)$ & $23(8.6)$ \\
\hline Continuity of care Physicians & $21(1.3)$ & $5(1.9)$ \\
\hline Hygiene \&Public Health & $190(11.6)$ & $40(14.9)$ \\
\hline Pediatrics & $174(10.6)$ & $29(10.8)$ \\
\hline Psychiatry & $118(7.2)$ & $19(7.1)$ \\
\hline Sports Medicine & $68(4.2)$ & $12(4.5)$ \\
\hline Genetics & $60(3.7)$ & $1(0.4)$ \\
\hline Occupational Health Medicine & $54(3.3)$ & $12(4.5)$ \\
\hline Gynecology and obstetrics & $53(3.2)$ & $3(1.12)$ \\
\hline Other specialties & $580(35.4)$ & $95(35.5)$ \\
\hline \multicolumn{3}{|l|}{ Professional status } \\
\hline Private health facilities/NHS Employees & $913(55.8)$ & $148(55.2)$ \\
\hline Freelancers & $337(20.6)$ & $49(18.3)$ \\
\hline Private contractors with NHS & $359(21.9)$ & $64(23.9)$ \\
\hline Without occupation & $28(1.7)$ & $7(2.6)$ \\
\hline
\end{tabular}


Among the Completers, 790 (48.3\%) were male and 847 (51.7\%) females. The median age was 56 years and the most represented age group was 51-65 years (58.3\%). Most of the participants were from the South of Italy (including Islands) (38.5\%), followed by North (36.3\%) and Center (25.2\%). The most represented disciplines were those referring to "primary care" (GPs, FPs, and Continuity of care Physicians), accounting for the $20.8 \%$ of participants, followed by "hygiene, epidemiology, health organization" (11\%), specialist pediatricians (10.6\%), "psychiatry and psychotherapy" (7.2\%), "sports medicine" (4.2\%), "genetics and laboratory genetics" (3.7\%), "occupational medicine" (3.3\%) and "gynecology and obstetrics" (3.2\%). Regarding the professional status, most of the participants were private health facilities or NHS Employees (55.8\%).

The Respondents at follow-up were 268 out of 1637 (16.4\%). Among them, 145 (54.1\%) were males and $123(45.9 \%)$ females. The mean age was 55 years and the most represented age group was 51-65 years $(63.8 \%)$. Most of the participants came from the North of Italy (37.7\%), followed by South (37.3\%) and Center (25\%). The most represented disciplines were "primary care" (23.5\%), "hygiene and public health" $(14.9 \%)$ and specialist pediatricians $(10.8 \%)$. As for the professional status, most of the participants were private health facilities/NHS Employees (55.2\%).

\section{Effectiveness of the course}

The preliminary question on a previous attendance to similar training courses indicates that $79.4 \%$ of participants had not attended other courses on the same topic before. The results of the pre-test versus post-test comparison are reported in Table 3. A significant improvement was recorded in $100 \%$ of the questions.

Table 3. Knowledge level of the Completers before and after the course ( $N=1637)$. 


\begin{tabular}{l|l|l|l|l}
\hline $\mathbf{N}^{\circ}$ & \multicolumn{1}{|c|}{ Question } & $\begin{array}{c}\text { Correct answers } \\
\text { before the course } \\
\text { (T0) } \\
\mathbf{N}(\%)\end{array}$ & $\begin{array}{c}\text { Correct answers } \\
\text { after the course } \\
\text { (T1) } \\
\mathbf{N}(\%)\end{array}$ & p-value \\
\hline 1 & $\begin{array}{l}\text { Which of the following groups of diseases is characterized } \\
\text { by the interaction between genes and the environment? }\end{array}$ & $\begin{array}{c}917(56.0) \\
1116(68.2)\end{array}$ & $<0.0001$ \\
\hline 2 & $\begin{array}{l}\text { What is the name of the study of DNA polymorphisms in } \\
\text { order to predict the safety and efficacy of drugs? }\end{array}$ & $1319(80.6)$ & $1497(91.5)$ & $<0.0001$ \\
\hline 3 & $\begin{array}{l}\text { Is the evaluation of the hereditary-family risk of a tumor } \\
\text { carried out as part of the oncological screening pathways? }\end{array}$ & $515(31.5)$ & $866(52.9)$ & $<0.0001$ \\
\hline 4 & What is a predictive test? & $1261(77.0)$ & $1332(81.4)$ & 0.0026 \\
\hline 5 & What are the main models of Mendelian heritage? & $1446(88.3)$ & $1522(93.0)$ & $<0.0001$ \\
\hline 6 & What do pharmacogenetic tests predict? & $1263(77.2)$ & $1479(90.4)$ & $<0.0001$ \\
\hline 7 & $\begin{array}{l}\text { What coverage does participation in cancer screening } \\
\text { programs for breast and colorectal cancer reach in our } \\
\text { country? }\end{array}$ & $336(20.5)$ & $619(37.8)$ & $<0.0001$ \\
\hline 8 & $\begin{array}{l}\text { In hereditary forms of cancer, what is the transmission of } \\
\text { the gene involved? }\end{array}$ & $705(43.1)$ & $879(53.7)$ & $<0.0001$ \\
\hline 9 & $\begin{array}{l}\text { What types of analysis are performed with Next } \\
\text { Generation Sequencing (NGS) techniques? }\end{array}$ & $678(41.4)$ & $911(55.7)$ & $<0.0001$ \\
\hline 10 & $\begin{array}{l}\text { What is the role of diagnostic genetic tests in the field of } \\
\text { hereditary tumors? }\end{array}$ & $1294(79.1)$ & $1471(89.9)$ & $<0.0001$ \\
\hline & & & \\
\hline
\end{tabular}

Table 4 presents the results of the comparison between average pre-test (T0) and post-test (T1) scores according to the participants' characteristics. The average overall pre and post-test scores were 59.5 and 71.4, respectively, with a mean increase of 11.9 (p-value <0.0001). In stratified analysis, a significant improvement in the average scores was recorded for all the categories considered. The stratified analysis by age shows that, with increasing age, the pre-test score was lower, along with a progressive increase in the difference between average pre-test and post-test scores. The stratification by region of residence demonstrates a North-South decreasing gradient both in the pre-test score and in the score increase between post-test and pre-test. The stratified analysis by medical discipline shows the greatest increase in knowledge for "sports medicine physicians" (score increase 15.3) and for the class of physicians belonging to "primary care" (14.3). These classes had the lowest pre-test scores (53.1 "sports medicine physicians" and 57.0 "primary care" physicians). Within the "primary care" class, GPs had the lowest pretest score (56.3) and achieved the greatest increase (score increase 15.3) (data not shown). With regard to professional status, the highest increase in scores was recorded for the private contractors with the NHS (14.4), that were those who had the lowest pre-test score (57.9).

Table 4. Completers' pre-test versus post-test average scores according to several participants' characteristics. 


\begin{tabular}{|c|c|c|c|c|}
\hline & $\begin{array}{l}\text { Pre-test (T0) mean } \\
\text { score }\end{array}$ & $\begin{array}{l}\text { Post-test (T1) mean } \\
\text { score }\end{array}$ & Difference & p-value \\
\hline Overall (N=1637) & 59.46 & 71.42 & 11.96 & $<0.0001$ \\
\hline \multicolumn{5}{|l|}{ Gender } \\
\hline Male $(\mathrm{N}=790)$ & 60.28 & 72.77 & 12.49 & $<0.0001$ \\
\hline Female $(\mathrm{N}=847)$ & 58.70 & 70.17 & 11.46 & $<0.0001$ \\
\hline \multicolumn{5}{|l|}{ Age } \\
\hline$<56$ years $(\mathrm{N}=814)$ & 61.81 & 72.33 & 10.53 & $<0.0001$ \\
\hline$\geq 56$ years $(\mathrm{N}=823)$ & 57.14 & 70.52 & 13.38 & $<0.0001$ \\
\hline \multicolumn{5}{|l|}{ Region } \\
\hline North $(\mathrm{N}=594)$ & 60.24 & 73.38 & 13.15 & $<0.0001$ \\
\hline Center $(\mathrm{N}=413)$ & 59.54 & 71.94 & 12.40 & $<0.0001$ \\
\hline South $(N=630)$ & 58.68 & 69.24 & 10.56 & $<0.0001$ \\
\hline \multicolumn{5}{|l|}{ Medical specialty } \\
\hline Primary care $(\mathrm{N}=340)$ & 56.97 & 71.29 & 14.32 & $<0.0001$ \\
\hline Hygiene \&Public Health $(\mathrm{N}=190)$ & 60.21 & 70.63 & 10.42 & $<0.0001$ \\
\hline Pediatrics $(\mathrm{N}=174)$ & 62.59 & 73.68 & 11.09 & $<0.0001$ \\
\hline Psychiatry $(\mathrm{N}=118)$ & 57.97 & 70.68 & 12.71 & $<0.0001$ \\
\hline Sport Medicine $(\mathrm{N}=68)$ & 53.09 & 68.38 & 15.29 & $<0.0001$ \\
\hline Genetics $(\mathrm{N}=60)$ & 72.83 & 83.5 & 10.67 & $<0.0001$ \\
\hline Occupational Health Medicine $(\mathrm{N}=54)$ & 58.89 & 68.33 & 9.44 & 0.0005 \\
\hline Gynecology and obstetrics $(\mathrm{N}=53)$ & 63.40 & 72.26 & 8.87 & 0.0017 \\
\hline Other specialties $(\mathrm{N}=580)$ & 59.10 & 70.55 & 11.45 & $<0.0001$ \\
\hline \multicolumn{5}{|l|}{ Professional status } \\
\hline $\begin{array}{l}\text { Private health facilities/NHS Employees } \\
(\mathrm{N}=913)\end{array}$ & 59.55 & 71.04 & 11.49 & $<0.0001$ \\
\hline Freelancers $(\mathrm{N}=337)$ & 60.68 & 71.39 & 10.71 & $<0.0001$ \\
\hline Private contractors with the NHS $(\mathrm{N}=359)$ & 57.86 & 72.23 & 14.37 & $<0.0001$ \\
\hline Without occupation $(\mathrm{N}=28)$ & 62.5 & 73.93 & 11.43 & 0.0039 \\
\hline
\end{tabular}

Table 5 and Table 6 report the results of the Respondents at follow up (T2) test.

Regarding the knowledge, with the exception of the question 4 and 5, improvement was recorded when comparing the correct answers at T1 and at T2 with respect to the pre-test (T0) (Table 5). The statistical analysis comparing the correct answers given in T2 vs T0 demonstrated a significant knowledge retain for 6 of the 10 questions $(p<0.05)$ (Table 5$)$.

Table 5. Knowledge level of the Respondents before (T0), after (T1) the course and at follow-up (T2) and comparison between T2 and T0 $(\mathrm{N}=268)$. 


\begin{tabular}{|c|c|c|c|c|c|}
\hline $\mathbf{N}^{\circ}$ & Question & $\begin{array}{c}\text { Respondents } \\
\text { who gave } \\
\text { correct answers } \\
\text { at } \\
\text { T0 } \\
\text { N (\%) }\end{array}$ & $\begin{array}{c}\text { Respondents } \\
\text { who gave } \\
\text { correct answers } \\
\text { at } \\
\text { T1 } \\
\text { N (\%) }\end{array}$ & $\begin{array}{c}\text { Respondents } \\
\text { who gave } \\
\text { correct answers } \\
\text { at } \\
\text { T2 } \\
\text { N (\%) }\end{array}$ & $\begin{array}{c}\text { T2 vs T0 } \\
\text { p-value }\end{array}$ \\
\hline 1 & $\begin{array}{l}\text { Which of the following groups of diseases is } \\
\text { characterized by the interaction between } \\
\text { genes and the environment? }\end{array}$ & $150(56.0)$ & $190(70.9)$ & $180(67.2)$ & 0.0030 \\
\hline 2 & $\begin{array}{l}\text { What is the name of the study of DNA } \\
\text { polymorphisms in order to predict the safety } \\
\text { and efficacy of drugs? }\end{array}$ & $210(78.4)$ & $249(92.9)$ & $231(86.2)$ & 0.0115 \\
\hline 3 & $\begin{array}{l}\text { Is the evaluation of the hereditary-family } \\
\text { risk of a tumor carried out as part of the } \\
\text { oncological screening pathways? }\end{array}$ & $64(23.9)$ & $144(53.7)$ & $108(40.3)$ & $<0.0001$ \\
\hline 4 & What is a predictive test? & $217(81.0)$ & $217(81.0)$ & $209(78.0)$ & 0.3827 \\
\hline 5 & $\begin{array}{l}\text { What are the main models of Mendelian } \\
\text { heritage? }\end{array}$ & $243(90.7)$ & $252(94.0)$ & $238(88.8)$ & 0.4561 \\
\hline 6 & What do pharmacogenetic tests predict? & $210(78.4)$ & $246(91.8)$ & $228(85.1)$ & 0.0290 \\
\hline 7 & $\begin{array}{l}\text { What coverage does participation in cancer } \\
\text { screening programs for breast and } \\
\text { colorectal cancer reach in our country? }\end{array}$ & $53(19.8)$ & $93(34.7)$ & $49(18.3)$ & 0.6276 \\
\hline 8 & $\begin{array}{l}\text { In hereditary forms of cancer, what is the } \\
\text { transmission of the gene involved? }\end{array}$ & $119(44.4)$ & $146(54.5)$ & $125(46.6)$ & 0.5839 \\
\hline 9 & $\begin{array}{l}\text { What types of analysis are performed with } \\
\text { Next Generation Sequencing (NGS) } \\
\text { techniques? }\end{array}$ & $100(37.3)$ & $153(57.1)$ & $144(53.7)$ & $<0.0001$ \\
\hline 10 & $\begin{array}{l}\text { What is the role of diagnostic genetic tests } \\
\text { in the field of hereditary tumors? }\end{array}$ & $204(76.1)$ & $242(90.3)$ & $222(82.8)$ & 0.0366 \\
\hline
\end{tabular}

Table 6 reports the results of the Respondents to the additional question on the perceived competence about the acquired capability to meet patient requests on genetic tests. Among the Respondents, the perceived competence has improved overall: those who felt less competent were $45.2 \%$ at the pre-test, $41 \%$ at post-test and $28.2 \%$ at follow-up; the number of Respondents who felt more capable of providing information increased from $18.2 \%$ in the pre-test to $19.5 \%$ and $22.4 \%$ in the post-test and follow-up, respectively.

Table 6. Respondents' answers on the perceived competence about the capability to meet the patients request on genetic tests $(\mathrm{N}=268)$ 


\begin{tabular}{l|c|c|c}
\hline When asked by patients, I was able to provide information about & $\begin{array}{c}\text { Before } \\
\text { dhe } \\
\text { course } \\
(\mathrm{T} 0) * \\
\mathrm{~N}(\%)\end{array}$ & $\begin{array}{c}\text { After } \\
\text { the } \\
\text { course } \\
(\mathrm{T} 1) \\
\mathrm{N}(\%)\end{array}$ & $\begin{array}{c}\text { Eight months after the } \\
\text { course closes (T2) } \\
\text { N (\%) }\end{array}$ \\
\hline Never & $22(8.5)$ & 31 & $14(5.4)$ \\
\hline Rarely & 38 & 30 & $22(8.5)$ \\
\hline Occasionally & $(14.7)$ & $(11.7)$ & $16(6.2)$ \\
\hline Sometimes & $20(7.7)$ & $18(7.0)$ & $21(8.1)$ \\
\hline Regularly & $\begin{array}{c}37 \\
(14.3)\end{array}$ & $\begin{array}{c}26 \\
(10.2)\end{array}$ \\
\hline Usually & $22(8.5)$ & $21(8.2)$ & $33(12.8)$ \\
\hline Always & $17(6.6)$ & $18(7.0)$ & $20(7.7)$ \\
\hline Not applicable & $8(3.1)$ & $11(4.3)$ & $23(8.9)$ \\
\hline
\end{tabular}

* Referred to 12 months before the course start

\section{Satisfaction questionnaire results}

The majority of participants was satisfied with the learning method, with the adequacy of the contents and with the e-learning platform functioning. A high overall approval on the course emerged, considering that the scores attributed are all between 4 and 5 , where 5 express the highest degree of satisfaction (Figure 2).

\section{Discussion}

The aim of this study was to analyze the effectiveness of a distance learning course on genetics and genomics for Italian physicians. In recent years, a growing interest in promoting courses on genetics/genomics topics has clearly emerged [19,20], due to rapid developments in genomic technologies and to the insufficient knowledge of healthcare practitioners in this field [21-23]. A previous research about learning methodologies on genetics suggests that different aspects of an educational intervention may have an impact on its effectiveness, including the type of intervention and the amount of practice-reinforcing strategies it contains [15]. Indeed, interactive learning, including case studies, is generally more effective at improving medical knowledge than learning based on theoretical principles alone [24].

This course represents the second Italian experience in distance training in genomics [25].

The main innovative aspect of the "Genetics and Genomics practice" course is related to the teaching methodology, oriented to an active training. The PBL methodology encourages the participants to "learn to learn" by solving real-world problems that reflect their work context [11, 12]. Schmidt et al. [10] 
indicated that in PBL the presentation of a problem activates the participants' prior knowledge, enabling more effective learning to take place. Compared to a conventional approach, in PBL learning occurs in a more active way, since participants attempt to solve a problem and to identify the specific learning objectives themselves. Therefore, learners face a cognitive conflict and construct their learning on their previous knowledge and experience [26]. CBL encourages participants to integrate their learning in the context of realistic clinical environment and to connect theory to clinical practice. The learning theories applied to CBL derive mainly from adult-learning and inquiry-based learning approaches, relaying also to cognitive and social constructivist models [27]. Although in some studies CBL is contrasted to PBL in terms of structure, being guided-learning, we integrated these two approaches, in order to provide a comprehensive andragogical and active orientation to the course [28].

The results of our "Genetics and Genomics practice" course suggest that distance-learning training in genetic/genomic practice represents an effective and satisfactory method to improve physicians' knowledge across all age groups of participants. Among the 1637 participants who completed the course, the most represented age class was those of 51-65 years. This result may be related to the educational need of the over-50 age physicians in an innovative field as omics sciences. In fact, most healthcare professionals had not received an adequate training on this topic during their studies, as demonstrated by a negative correlation between time from medicine degree and omics sciences knowledge [29]. Participants declared their previous training experience on the course issues at the beginning of the course and results demonstrated that the majority of participants had never attended other courses on that topic before.

The effectiveness of the course was measured through a knowledge test made of a set of 10 MCQs that was repeated before the start and at the end of the course. The overall results suggest that the course improved the general level of knowledge. Nevertheless, as revealed by the stratified analysis, the improvement was not homogeneous for all the medical specialties. For example, the knowledge improvement was greater for Primary Care physicians and Sport Medicine physicians. These results accomplish our expectations regarding the course, since it was intended mainly as directed to GPs and FPs (primary care), that don't receive a specific education in genetics during their specialization, but deal with genetic problems during the daily practice. The low pre-test score of this specialty group confirmed the educational need we hypothesized in planning the course. As for Sport Medicine physicians, the lowest pre-test score they reported could be explained with the fact that they deal with genetics more rarely than other specialists; however, the great improvement obtained in the post-test score could demonstrate the effectiveness of the course in filling the knowledge gap. On the opposite, the Gynecologists and Occupational Medicine physicians reported the lowest difference between the pre and post-test. For the first category, this might be related to the high pre-test score they reported, while for the latest both the pre-test and the post-test scores were low, if compared to the overall scores. The highest pre-test and post-test scores were registered for the Geneticists, demonstrating their pre-existing knowledge on the topic. Our results are consistent with the results reported by Michelazzo et al. [22], that analyzed the effect of a previous course in genetics and genomics for physicians, organized with different educational methodologies.

Page $14 / 22$ 
To our knowledge, this is the first study that attempts to measure the knowledge retain and the educational effects of the course after a follow-up period. This was obtained by inviting all participants to complete the same pre/post-test after a follow-up period of eight months. Although the number of respondents was low if compared to the high number of the course completers (268 vs 1637), we can assume that this group is representative of the Completers, as the demographic and professional characteristics of the two groups were analogous.

The overall scores show that after eight months the knowledge level decreased if compared to the posttest score, but it was higher than the pre-test score. The statistical analysis comparing T2 vs T0 demonstrated an overall significant increase and retain in knowledge.

The follow-up data also allow some considerations on the self-perceived sense of competence of the medical professionals in giving information on genetic tests to patients, before and after the course. According to our results, the sense of competence improved at follow-up and there was an increase in the number of doctors who felt more capable of providing information about the diagnostic/prognostic utility of predictive genetic test.

Our study presents some limitations. Firstly, the effectiveness of the course could be overestimated, due to the fact that only data of those who completed the entire course were collected. Therefore, it might be possible that the "dropouts" would have reported lower improvements or less satisfaction than the "completers". Secondly, the sample size of those who completed the course was quite heterogeneous in terms of specialties, not allowing a significant representation of all the discipline categories, many of which were grouped into one "other specialties" category.

Despite these limitations, the results of our study confirmed the effectiveness of genetic and genomic courses in improving participants' literacy on omics sciences, not only in terms of knowledge, but also in terms of managing genetic information in daily practice. In particular, our results suggest that especially primary care physicians are those who can have the most important benefit from a course on this topic.

\section{Conclusions}

The course was characterized by some innovative aspects. First of all, as strongly requested by the Italian Ministry of Health, the course was direct to all the medical specialities, despite the specificity of such a current topic. Indeed, for the first time, a large number of various health professionals could access a learning project on "omics" sciences not reserved to specialists in genetics only. Moreover, we experimented a new methodological approach, consisting of a synergy between two different approaches, PBL and CBL.

In conclusions, in our experience a distance-learning training in genetic/genomic practices that adopts a PBL and CBL approach was highly effective to improve physicians' knowledge and self-perceived competence. 


\section{List Of Abbreviations}

MCQs: Multiple Choice Questions

PBL: Problem-based Learning

CBL: Case-based Learning

LMS: Learning Management System

GPs: General Practitioners

FPs: Family Pediatricians

CME: Continuous Medical Education

NHS: National Health Service

SQ: satisfaction questionnaire

\section{Declarations}

\section{Ethics approval and consent to participate}

According to institutional regulation in Italy, ethics committee approval was not required for this study: participants were informed about methods and aims of the study and, by registering for the course on the online platform, agreed to the use of anonymous data in accordance with Italian Data Protection Regulations (Legislative Decree no. 196/2003 amended by the decree adapting the national legal system to the GDPR 2016/679).

\section{Consent for publication}

Not applicable

\section{Availability of data and materials}

The datasets generated and analyzed during the current study are not publicly available, as personal information of the participants of the course are stored, but are available from the corresponding author on reasonable request.

\section{Competing interests}

The authors declare that they have no competing interests.

\section{Funding}


This work is supported by the Italian Center for Disease Control (Centro Nazionale per il Controllo delle Malattie CCM) of the Italian Ministry of Health within the project titled "Capacity building e cittadinomica: azioni innovative per la literacy di professionisti sanitari e cittadini nell'era delle scienze omiche" (Project reference n. CUP: 185B18001500005). The role of the funding bodies regards the publication of the manuscript.

\section{Authors' contributions}

SB and WR conceived the study and GEC, AT, AM, AF participated in its design. SB, GEC and AM developed the content of the distance learning course. AM, PC, DB, ADP, DG realised the course in the online platform and collected the participants' data. AT, GEC, AM, PC, DB, DG and ADP statistically analysed data. SB, GEC, AT, AM, PC, DB, DG and ADP critically discussed and interpreted the results of the knowledge tests.

All authors drafted and critically reviewed this manuscript and approved the final version.

\section{Acknowledgements}

We would like to thank Professor Bruno Dallapiccola, Professor Maurizio Genuardi and Professor Giuseppe Novelli for their contribution to the realization of the course.

\section{References}

1. Schneider MV, Orchard S. Omics technologies, data and bioinformatics principles. Methods Mol Biol. 2011; 719:3-30

2. Anderson MW, Schrijver I. Next Generation DNA Sequencing and the Future of Genomic Medicine. 2010; 1, 38-69

3. Muntoni F, Cross JH. Paediatric neurology: from molecular mechanisms to targeted treatments. Lancet Neurol. 2015; 14:16-8

4. Boccia S, Ricciardi W, McKee M, Federici A, Guerra R. Chief Medical Officers meeting on implementing a public health genomics approach. Epidemiol Biostat Public Health. 2015; 12:3

5. Mazzucco W, Pastorino R, Lagerberg T, Colotto M, d'Andrea E, Marotta C et al. Current state of genomic policies in healthcare among EU member states: results of a survey of chief medical officers. Eur J Pub Health. 2017;27(5):931-7.

6. Conferenza Stato-Regioni del 13.03.2013: Intesa tra il Governo, le Regioni e le Province autonome di Trento e di Bolzano sul documento recante: "Linee di indirizzo su la genomica in sanità pubblica". (SALUTE) Codice sito: 4.10/2013/32 (Servizio III) Intesa ai sensi dell'articolo 8, comma 6, della legge 5 giugno 2003, n. 131. http://www.regioni.it/sanita/2013/03/25/conferenza-stato-regioni-del-13-032013-intesa-tra-il-governo-le-regioni-e-le-province-autonome-di-trento-e-di-bolzano-sul-documentorecante-linee-di-indirizzo-su-la-genomica-in-sanita-pub-290494. Accessed 1 Dec 2019. 
7. Boccia S, Federici A, Colotto M, Villari P. Implementation of Italian guidelines on public health genomics in Italy: a challenging policy of the NHS. Epidemiol Prev. 2014 Nov-Dec;38(6 Suppl 2):2934.

8. Boccia S, Federici A, Siliquini R, Calabrò GE, Ricciardi W on behalf of the Expert table of the Ministry of Health. Implementation of genomic policies in Italy: the new National Plan for innovation of the Health System based on omics sciences. Epidemiol Biostat Public Health. 2017; 14(4)

9. Calabrò GE, Tognetto A, Mazzaccara A, Barbina D, Carbone P, Guerrera D, Federici A, Ricciardi W, Boccia S. Omic sciences and capacity building of health professionals: a distance learning training course for Italian physicians. Ig Sanita Pubbl. 2019 Mar-Apr;75(2):105-124.

10. Vaona A, Banzi R, Kwag KH, Rigon G, Cereda D, Pecoraro V, Tramacere I, Moja L. E-learning for health professionals. Cochrane Database of Systematic Reviews 2018; Issue 1. Art. No.: CD 011736.

11. Schmidt HG, Rotgans JI, Yew EHJ. The process of problem-based learning: what works and why. Medical Education 2011; 45: 792-806.

12. Mazzaccara A, Barbina D, Guerrera D. Problem-based learning in distance training for health professionals: a high interactivity model. Atti Conference Mediterranean MoodleMoot, 2nd and 3rd October 2013 - Sousse, Tunisia.

13. McLean SF. Case-Based Learning and its Application in Medical and Health-Care Fields: A Review of Worldwide Literature. J Med Educ Curric Dev. 2016; 27:3.

14. Tognetto A, Michelazzo MB, Ricciardi W et al. Core competencies in genetics for healthcare professionals: results from a literature review and a Delphi method. BMC Med Educ 19, 19 (2019) doi:10.1186/s12909-019-1456-7

15. Pastorino R, Calabrò GE, Lagerberg T, Michelazzo MB, Boccia S. Effectiveness of educational intervention types to improve genomic competency in non-geneticist medical doctors: a systematic review of the literature. Epidemiol Biostat Public Health. 2018. 15(1)

16. Azer SA. Assessment in problem-based learning. Biochem Mol Biol Educ 2003;31(6):428-434.

17. Tabish SA. Assessment methods in medical education. Int J Health Sci 2008;2(2):3-7.

18. Anderson LW, Krathwohl DR. A taxonomy for learning, teaching and assessing: a revision of bloom's taxonomy of educational objectives. New York: Longman; 2001.

19. Kohane I. Ten things we have to do to achieve precision medicine. 2015;349(6243):378. https://doi.org/10.1126/science.aab1328

20. Cornel M. Evidence-Based Genetic Education of Non-Genetic-Expert Physicians: Experiences Over Three Decades in Amsterdam. Frontiers in Genetics. 2019;10.

21. Feero WG, Green ED. Genomics education for health care professionals in the 21 st century. JAMA. 2011;306(9):989-90.

22. Boccia S. Why is personalized medicine relevant to public health? Eur J Public Health. 2014;24(3):349-50. 
23. Hall A, Luheshi L. Signatories: Prof. Bartha Maria Knoppers, Dr Eric Meslin, Prof. Walter Ricciardi, Dr Ron Zimmern. Personalised healthcare: bringing the future into focus. PHG Foundation. Final report of the Ickworth meeting, 2017. http://www.phgfoundation.org/documents/REPORT\%20\%20Personalised\%20healthcare\%20bringing\%20the\%20future\%20into\%20focus.pdf.Accessed 1 Dec 2019.

24. D'Alessandro DM, Lewis TE, D'Alessandro MP. A pediatric digital storytelling system for third year medical students: the virtual pediatric patients. BMC Med Educ. 2004 Jul 19 ;4(1):10.

25. Michelazzo MB, Roberta Pastorino R, Mazzucco W, Boccia S. Distance learning training in genetics and genomics testing for Italian health professionals: results of a pre and post-test evaluation. Epidemiol Biostat Public Health. 2015; 12(3):311516-1/6

26. Masek A, Yamin S. A Comparative Study of the Effect of Problem Based Learning and Traditional Learning Approaches on Students' Knowledge Acquisition. International Journal of Engineering Education 2012, 28:1161-1167.

27. Mayo JA. Using case-based instruction to bridge the gap between theory and practice in psychology of adjustment. J Constr Psychol 2004; 17(2)137-146.

28. Thistlethwaite JE, Davies D, Ekeocha S, Kidd JM, MacDougall C, Matthews P et al. The effectiveness of case-based learning in health professional education. A BEME systematic review: BEME Guide No. 23. Med Teach. 2012; 34(6):421-444.

29. Hofman KJ, Tambor ES, Chase GA, Geller G, Faden RR, Holtzman NA. Physicians' knowledge of genetics and genetic tests. Acad Med. 1993;68(8):625-32.

\section{Figures}


- N 3054 healthcare professionals (participants) enrolled

Enrollment

$\checkmark 1$

- N 2270 participants completed the mandatory Pre-test TO (N $10 \mathrm{MCQ}$ ) and answered to two additional questions (both not directed to specialists in medical genetics): 1)

Pre-test To previous learning experience on genetics and 2) perceived competencies on genetics

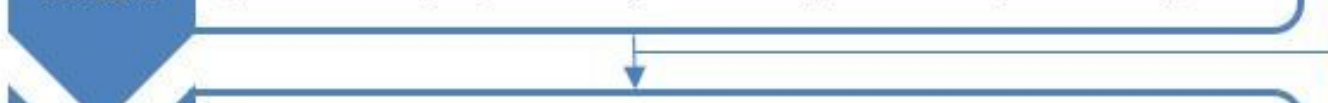

- N 2086 participants accessed to the Learning resources (exercise on problem analysis and learning objectives identification; support and study materials; tutorials; case studies; problem solution)

Course

attendance

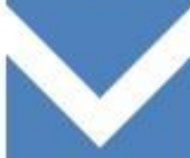

- N 1764 participants completed the mandatory Post-test T1 (N $10 \mathrm{MCQ}$ )

- N 1242 participants answered to the additional question (not directed to specialists in Post-test T1 medical genetics) on perceived competencies on genetics

N 968 Dropouts

N 322 Dropouts

-N 1637 participants (Completers) scored $>75 \%$ at CME Knowledge final evaluation
test (N $90 \mathrm{MCQ}$ )
and filled in the Satisfaction questionnaire, both mandatory to access to attendance
certificate - N 30 credits CME: SELECTED COHORT

\section{Figure 1}

Flowchart of cohort selection of participants. Note: CME: Continuous Medical Education; MCQ: Multiple Choice Questions 

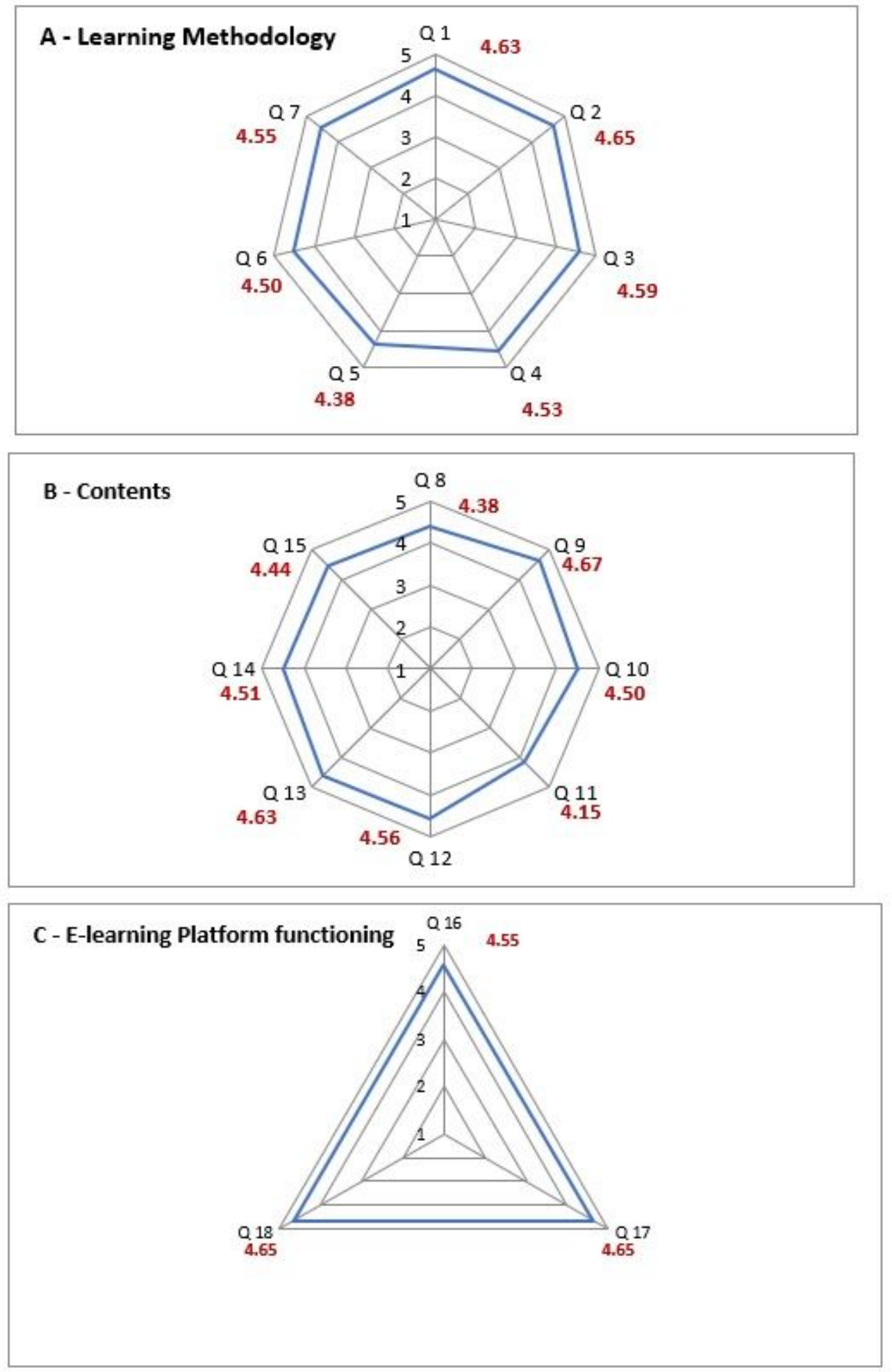

\section{Figure 2}

Satisfaction questionnaire results on contents and learning methodology of the course, and e-learning platform functioning. Notes: A - Learning Methodology: Q1 The objectives of the course were clear; Q2 The content was consistent with the objectives of the course; Q3 The teaching methodology was effective; Q4 The overall organization (course articulation, timing, intermediate and final evaluations) was satisfactory; Q5 The test questions were clear; Q6 The time available to perform the tests was adequate; 
Q7 The quality of tutoring for this FAD event was satisfactory B - Contents: Q8 The level of the course was appropriate to my knowledge; Q9 I have learned new concepts; Q10 I have acquired new skills; Q11 I can apply what I learned in this course in my working context; Q12 The documentation made available was adequate to acquire the necessary information; Q13 The quality of the documentation available was appropriate; Q14 The documentation available was updated to the most recent literature; Q15 The consultation of the participant's guide was useful in orienting myself in the educational path. C - Elearning Platform functioning: Q16. The quality of technical support has been satisfactory; Q17 The functioning of the platform was adequate; Q18 The access to the online platform was simple and immediate. 